\title{
Aqueous Synthesis of Thiol-Capped CdTe Nanocrystals: State-of-the-Art
}

Andrey L. Rogach,* Thomas Franzl, Thomas A. Klar, and Jochen Feldmann

Photonics and Optoelectronics Group, Physics Department and Center for NanoScience (CeNS),

Ludwig-Maximilians-Universität München, Amalienstr. 54, D-80799 Munich, Germany

Nikolai Gaponik,* Vladimir Lesnyak, Alexey Shavel, and Alexander Eychmüller

Physical Chemistry, TU Dresden, Bergstr. 66b, D-01062 Dresden, Germany,

Yuri P. Rakovich and John F. Donegan

Semiconductor Photonics Group, Department of Physics, and CRANN Research Institute, Trinity

College Dublin, Dublin 2, Ireland

\section{Supporting Information}

\section{Electrochemical generation of $\mathrm{H}_{2}$ Te gas used for the synthesis of CdTe nanocrystals}

In our experiments the hydrogen telluride was produced by electrochemical reduction of a tellurium electrode in the electrochemical cell at room temperature according to the following reaction:

$$
\mathrm{Te}^{0}+2 \mathrm{H}^{+}+2 \mathrm{e}^{-\rightarrow} \mathrm{H}_{2} \mathrm{Te} \uparrow \quad \mathrm{E}_{0}=-0.51 \mathrm{~V}[1]
$$

The electrochemical cell was equipped with a Te cathode and a Pt anode. The anode compartment was separated from the cell by a porous glass membrane. $50 \mathrm{wt} \%$ solution of the $\mathrm{H}_{3} \mathrm{PO}_{4}$ was used as the electrolyte. Figure $\mathrm{S} 1$ shows the details of the experimental setup. 


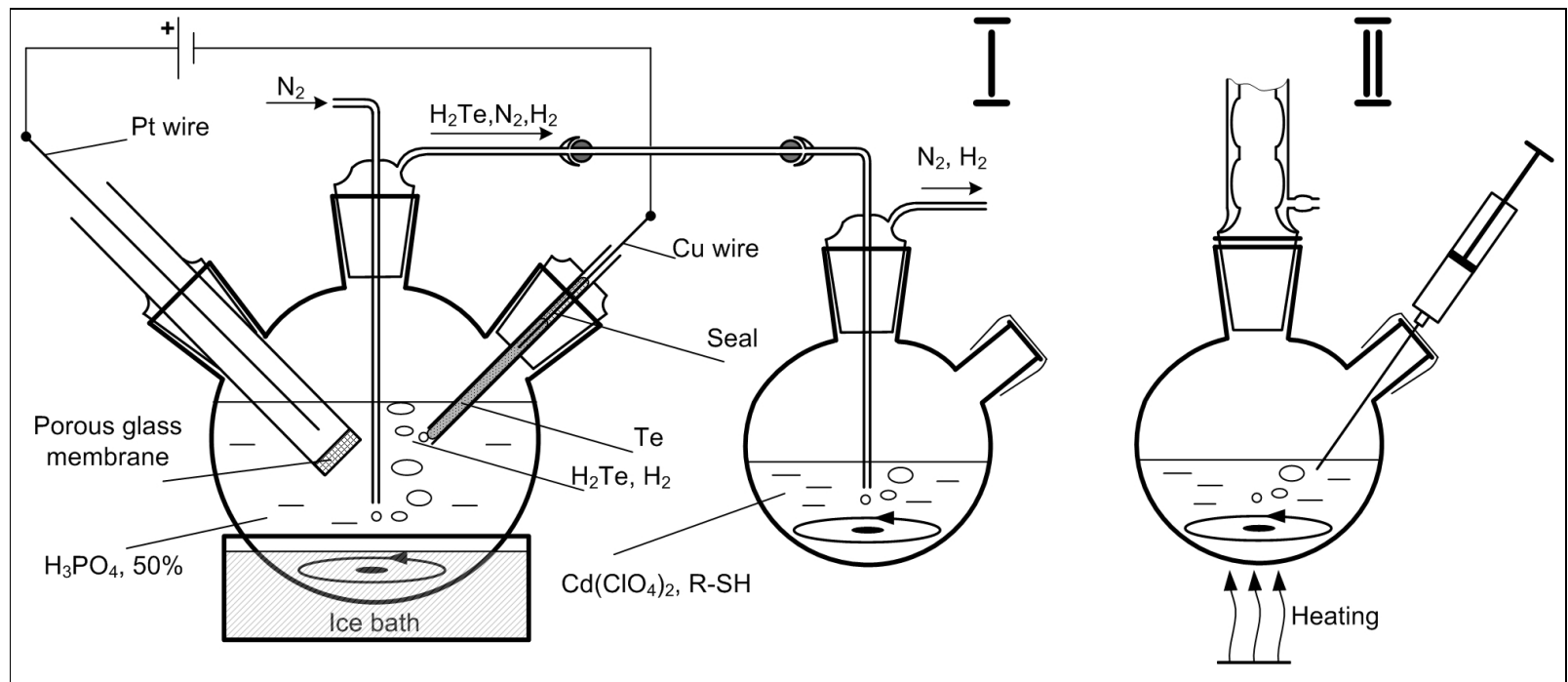

Figure S1. Experimental setup for electrochemical synthesis of the $\mathrm{H}_{2} \mathrm{Te}$.

The Te electrode was prepared as follows: Tellurium lumps (powder, Fluka) were placed in the glass tube and melted. A Pt contact wire was placed in the liquid tellurium. After cooling to room temperature, the empty part of the tube was sealed by epoxy resin and the glass end of tube was carefully broken providing a "naked" Te-surface.

Refs. $[2,3,4]$ use this reaction at low temperature $\left(-5 C^{o}\right.$ to $\left.-10 C^{\circ}\right)$ in order to avoid decomposition of the $\mathrm{H}_{2}$ Te gas. At the current density used $\left(380 \mathrm{~mA} / \mathrm{cm}^{2}\right)$ and at room temperature we did not find this effect to be significant.

In order to calculate the amount of $\mathrm{H}_{2} \mathrm{Te}$ one may use following equation:

$$
v=\mathrm{It} \eta / 2 \mathrm{~F}
$$

(I - current strength, $\mathrm{F}=$ 96484.56: Faraday constant, $\eta$ - electrochemical efficiency, $\mathrm{t}$ - duration of the experiment).

In order to estimate the effectiveness of our cell the followed experiment was carried out: $100 \mathrm{ml}$ of cadmium nitrate solution $(0.04 \mathrm{M})$ was placed in a three-necked flask fitted with a septum and valves and was de-aerated by Ar bubbling for 1.0 hours. The desired amount of $\mathrm{H}_{2} \mathrm{Te}$ gas was passed through the solution, controlled by the duration of electrolysis (at $380 \mathrm{~mA} / \mathrm{cm}^{2}$ current strength). In order to remove all dissolved $\mathrm{H}_{2}$ Te gas, the flow of Ar was maintained for 30 additional minutes. The precipitate of CdTe was filtered out, washed with bi-distilled water, dried and weighed. The efficiency of our cell was 35\% which is less than was published by Hodes for $50 \% \mathrm{H}_{2} \mathrm{SO}_{4}$ electrolyte [4]. Altering the electrochemical efficiency during long term 
use of the Te electrode can not be excluded [4]. Thus, periodic calibration of the electrochemical efficiency of the cell is necessary.

References

1. Lur'e, Y.Y., Handbook on Analytical Chemistry. 6th ed. 1989, Moscow, USSR: Khimiya. $446 \mathrm{pp}$.

2. Kovalenko, M.V., et al., Spectral, Optical, and Photocatalytic Characteristics of Quantum-Sized Particles of CdTe. Theoretical and Experimental Chemistry (Translation of Teoreticheskaya i Eksperimental'naya Khimiya), 2004. 40(4): p. 220-225.

3. Kovalenko, M.V., et al., Colloidal HgTe Nanocrystals with Widely Tunable Narrow Band Gap Energies: From Telecommunications to Molecular Vibrations. J. Am. Chem. Soc., 2006. 128(11): p. 3516-3517.

4. Bastide, S., et al., Electrochemical preparation of $\mathrm{H}_{2} \mathrm{~S}$ and $\mathrm{H}_{2} \mathrm{Se}$. J. Electrochem. Soc. 2005. 152(3): p. D35-D41. 